DOI: https://doi.org/10.47264/idea.lassij/4.1.16

Vol. 4, No. 1, (January-June 2020): 171-188

Research Article

URL: https://www.ideapublishers.org/index.php/lassij

\title{
Rehabilitation of Children with Intellectual Disability: Challenges in Social Skills Training in Khyber Pakhtunkhwa, Pakistan
}

\author{
Shakeel Ahmad ${ }^{1} \&$ Abida Bano*2
}

1. Department of Social Work, Faculty of Social Sciences, University of Peshawar, Pakistan.

2. Institute of Peace \& Conflict Studies, University of Peshawar, Peshawar, Pakistan.

\begin{abstract}
Intellectual disability among children is on the rise with no proper social skills training facilities around the province - Khyber Pakhtunkhwa. Special education institutions have been established to rehabilitate differently abled children; however, their focus is more on children's literacy with a physical disability. Resultantly, children with intellectual disabilities constitute a 'minority group' within the province's differently abled population. Consequently, children with intellectual disabilities remain excluded. The qualitative study aims to examine the quality of the state-sponsored special education institutions, emphasizing on social/life skill training services for children with intellectual disabilities. Based on a total of 25 individual interviews and observations from five selected districts, it is argued that despite the growing number of children with intellectual disabilities, the services are limited to physiotherapy services only. Speech therapies and social skills training are almost non-existent in the public sector special education institutes. Lack of a clear government policy and sufficient funding results in scarce resources, including trained staff, coupled with poor social welfare and special education services, which intensifies the problem. Engaging empowerment theory of Julian Rappaport (1977), the study recommends providing all essential services to children with ID for enabling and living an empowered life.
\end{abstract}

Keywords: Differently-abled Children, Intellectual Disability, Daily Living Skills, Social Skills Training, Public Sector Institutes, Rehabilitation Institutes.

\section{Introduction}

The mutually beneficial and reinforcing behaviours for social interactions are the social skills (Morgan \& Jenson, 1988). Usually, the deficit in social skills is a co-occurrence with the intellectual disability (hereafter referred to as ID) that shows delayed communication and less social interactions (Carter et al., 2010). The impaired social skills limit the opportunities for acceptance, meaningful interaction with peers, and class performance among children with ID (Cobb \& Alwell, 2009; Hughes et al., 2011). Studies show that children with ID need intervention and social support for better performance at high schools (O' Handley et al., 2016). Scholars suggest that school-based social skills training (SST) allows for better results among children with IDs since they are in an environment where social interactions with their peers frequently happen (Kern et al., 2002). Thus, the educational institutions for differently abled children play a crucial role in their social acceptance, meaningful interaction, better communication and independence. 
Until the late $18^{\text {th }}$ century, families would usually hide any child with intellectual disability from the public eye for shame and humiliation it might bring to the family (Ahmed, 2015). There were no treatment, cure, or care plans for such persons. Such children would be termed "mentally retarded" and were known as "possessed by demons" (Pritchard, 1963). However, later the $19^{\text {th }}$ centuries developments, particularly in the West, established large institutions for persons with intellectual disability. The emerging research concerning the issues of learning and intellectual disabilities among children and adolescents has spread the awareness and realized the need to institutionalize special skills training for children with IDs.

Children with learning disabilities usually lack appropriate social skills that adversely affect their social functioning (Brooks et al., 2015). Studies suggest that children with disabilities demonstrate higher social competency when intervened through SST in special schools and unique environments (Brooks et al., 2015; Browning et al., 2011; Sukhodolsky \& Butter, 2007; Rao \& Suryaprakasam, 2004; Spence, 2003). Spence argues that SST has become one of the most used intervention methods to change behavioural and developmental disorders. According to another study results, participation in unstructured activities and teamwork are positively correlated with the social development in children with learning disabilities (Brooks et al., 2015; Rao \& Suryaprakasam, 2004).

Social skills training - SST is also known as an adaptive skills or behaviour, which refers to applying the necessary academic skills learned in the school to perform daily activities. A child must also develop appropriate reasoning, judgment, and social skills that promote positive interpersonal relationships (Drew et al., 1986). Adaptive skills content area for elementary-age children with ID including motor, self-care, social, communication, and functional academic skills. The development of gross and fine motor skills is a prerequisite to successful learning in other adaptive areas. Gross motor skills development relates to general mobility, such as balance and locomotor patterns. It also includes neck and head control, rolling, body righting, sitting, creeping, crawling, standing, walking, running, jumping, and skating. Sufficient motor training includes learning to reach, grasp and manipulate objects (Denny, 1964). Such educational programming has been expanded to include the learning of adaptive skills necessary to decrease individuals' dependence on others and increase their living space (Drew et al., 1986). If the children are not formally taught skills with ID, they will not learn (Barnard \& Powell, 1972).

In societies with limited resources and inadequate governmental support, families, and communities provide social and welfare services to children with IDs. However, lack of technical resources such as trained staff, SST institutes, and many children remain unattended and professionally untrained, leaving them dependent for life. Studies show that most families and communities provide exceptional services to children with ID in India, while some NGOs are also engaged in providing services instead of the government (Browning et al., 2011; Rao $\&$ Suryaprakasam, 2004). However, research also shows that providing care and training to children with IDs is challenging and causes depression and anxiety among parents when done at home (Machalicek et al., 2015). Research suggests that intervention focusing on developing strategic parental skills and training reduces parental anxiety and stress and indirectly benefits children with behavioural problems having an intellectual disability (Crnic et al., 2017). The growing literature on children with IDs and their social competence found that family, community, and social welfare institutions through life skills training play a vital role in children's social development with IDs. 
Additionally, globalization and the subsequent escalation of the neoliberal economic agenda in every corner of the world have transformed social life (Murray, 2009). The traditional welfare agencies like extended or joint family, local community, and the church have weakened and runs the risk of extinction. These politico-economic dynamics reshaped traditional societies in developing countries such as Pakistan, which has become an 'emerging market' where institutional care is in high demanded to enable the destitute and vulnerable segments such as the person with a disability more productive and self-sufficient (Ali \& Naz, 2018). This realization led to the educational provisions for children with intellectual disabilities uncommon a few decades ago. Also, the United Nations' institutionalizing of child and persons with disabilities' rights has made it binding on the governments to take concrete measures to help children and differently-abled persons become productive citizens and self-reliant individuals. The United Nations Convention on the Rights of Child - UNCRC (1990), Article 23 states that the state must ensure the right to benefit from special care and education for a fuller life in society. Article 4 further dictates that the state should ensure that the rights mentioned in the Convention.

More specifically, the UN enacted a special convention for persons with a disability known as 'the Convention on the Rights of Persons with Disability (2005) ${ }^{1}$. Article 7 of the Convention on PWD states that "states parties shall take all necessary measures to ensure the full enjoyment by children with disabilities of all human rights and fundamental freedoms on an equal basis with other children." Moreover, in all actions concerning children with disabilities, the child's best interests shall be a primary consideration. Recognizing these realities, the educational provisions for children with intellectual disabilities also started expanding globally. However, the quality and quantity of services require evaluation to check if they are on par with the modern training standards.

\section{Statement of the Problem}

The situation of children with ID in Pakistan is in the doldrums. According to an Autism Resource Centre (ARC) survey report, approximately 350,000 autistic children in Pakistan, one out of 66 children, are autistic (Dawn, April 5, 2015). Similarly, the magnitude of such disabilities among children in KP is on the rise. According to a survey report, the most common types of disease and disabilities identified among children were fits, mental retardation, and difficulty speaking (Govt. of Khyber Pakhtunkhwa, 211: 12). Similarly, article 38 (sub-section d \& e), the constitution of 1973 of Pakistan, also focuses on the welfare and social protection of society's vulnerable and destitute segments. In the light of international and national commitments and laws, it is imperative to assess the services delivered to persons with disabilities since the number of such children is alarmingly increasing. The adequate provision of educational services for children with an intellectual disability depends on the knowledge of several children who need such services (Allen -Ile et al., 1997). In Pakistan, the exact number of intellectually disabled is unknown due to the lack of an official census regularly. According to the 1998 Census, 3,293,155 people had some disability (Annexure I, Table 1).

The public special education schools face the challenges of providing quality SST to children with intellectual disabilities consistent with their developmental needs. The lack of SST and social competence education cause developmental and behavioural disorders in children and adolescents (Spence, 2003). Experts now recognize that intellectual disability is not a life-long process. Specific kinds of intellectual disabilities might reduce social and other functioning at 
the initial life stage. However, with gradual training and education, the functional disability can be reduced significantly. This realization resulted in the development of special education for children with intellectual disabilities.

\section{Theoretical Framework}

Julian Rappaport initially coined empowerment theory - an American psychologist who introduced it into social work and social psychiatry and defined it as the degree of autonomy and self-determination in people and communities (Rappaport, 1977). According to Keiffer (1984), empowerment is an interactive process between the individual and his/her environment. A conducive environment paves the way to empowering those who suffer from various disabilities (environmental, social, psychological, and physical). Empowerment also refers to the empowerment of the vulnerable, weak, or people with disability will not embark on an empowerment process without creating the minimal condition of managing to surround. The empowerment theory's primary focus is making the surrounding conducive for the children with intellectual disability who require a sensitive, attentive, empathetic attitude for making such children enable to have control over their own life (Rose \& Black, 1985). Four major obstacles prevent children with intellectual disability from empowerment and rehabilitation (Moran et al., 2014; Moran \& Block, 2010):

- Lack of effective programs and opportunities for such children's upbringing both at community and institutions' level,

- Fear and lack of interest on the part of parents and special education instructors,

- Insufficient capacity of special education teachers in terms of training, skill, and knowledge

- Concerning liability.

\section{Research Methodology}

A qualitative study helps to assess the social and adaptive skills, and training, including selfcare, social, communication, and functional academic skills, available for children with ID at the public-sector education institutions in KP. As Peter and Waterman (1982) said, "stories than by date more influence us." Thus, the study uses a qualitative design with an inductive approach to focus more on the richness of data than the amount or enormity of data. The data was collected from five public sector special education centres from four selected districts of KP. These centres are established to provide unique training such as life skills and social development to Physically \& Mentally Retarded Children from the list provided by the Directorate of Social Welfare \& Special Education, Khyber Pakhtunkhwa. The names of the selected centres are:

- Section for Mentally Retarded Children at Special Education Complex Hayatabad, Peshawar.

- Centres for Physically and Mentally Retarded Children, Bashir Abad, Peshawar.

- Centre of Physically and Mentally Retarded Children, District Nowshera.

- Section for Mentally Retarded Children at Special Education Complex, Sheikh Maltoon, District Mardan.

- Centre of Physically and Mentally Retarded Children, District Haripur. 
The study uses qualitative interviews as the primary tool of data collection. A total of twentyfive officials, including social caseworkers, therapists, teachers, and heads of the institutes/principles, were selected purposively from the selected institutes of various districts for the in-depth individual interviews (see Annexure I, Table 2). The respondents were contacted through formal and informal sources. Verbal consent was taken for the interview. An unstructured interview guide with no specific order of questions is used to conduct interviews with the respondents. The researchers had a few thematic areas incorporated in the interview guide to generating discussion on the issue at fore with the research participants.

Moreover, an unstructured observation was also administered during the data collection process. The research respondents were government officials, so their identity is somewhat public, but the data is anonymized for confidentiality purposes. The condition of equipment and other services were captured through a picture taken on the cell phone. The interviews were recorded with the help of an audio recorder with the consent of the respondents. Data is encrypted and kept safe with the researchers. After completing interviews, data were transcribed, analyzed through developing themes.

\section{Results and Discussion}

This section includes the thematic analysis with a particular emphasis on the field reflections and their analysis. The discussion is divided into essential and recurring themes that emerged from the data. The availability of services at the selected centres is also given in table form in Annexure I, Table 3.

\subsection{The Magnitude of Intellectual Disability is Higher than other Disabilities but is given the least Preference}

The study found that the number of children with intellectual disabilities was much higher than children with other disabilities like physical or orthopaedic disabilities. However, the problem has not been recognized by the state or society in general. These children are receiving inadequate services, which causes issues in their rehabilitation. One of the research participants who was heading one of the special education facilities stated that:

The number of children with an intellectual disability is increasing day by day as compared to polio-affected children. We provide physiotherapy services to 10-15 children as an out-door-patient (OPD) per week. Out of which, 90\% to $95 \%$ of children suffered from mental retardation.

Similarly, another respondent who provides physiotherapy services at one of the centres said,

There are around 83 children who have physical disabilities, while more than 250 children have either MR or hearing disability (Field Notes, 2016).

One of the study participants from another centre in district Peshawar noted:

We provide services to children with disabilities; however, mental retardation or intellectual disability constitutes $95 \%$ compared to physical disability (Field Notes, Peshawar, 2016). 
Almost all the officials at the special educational centres agreed that the number of children with IDs is increasing in KP, and there is no proper government arrangement to give away much-needed services for their social development. The second most prevalent disability found in the study was hearing impairment among the children. Nevertheless, both at prevalence and rehabilitation or training, children with ID are entirely ignored at the society level. The government is focusing only on preventing polio cases through vaccination.

Moreover, special education institutes provide services to children with physical disabilities where physiotherapy-related training and equipment are available while other related resources required for dealing with children's intellectual disability were non-existent. Studies show that the social deficits in the children with IDs become vivid at the high school, which can be reduced by providing the needed social support at the institutions (Cobb \& Alwell, 2009; Elliot, et al., 2002). The school or centres' environment pushes the children with IDs to make social connections and engage in social communication. An increase in children with intellectual disabilities requires more special education centres that focus on SST, among other social development activities.

\subsection{Outdated and Irrelevant Equipment and Services for Rehabilitating Children with ID at the Centres}

Special education institutions exist in different districts, where the number of children with ID is higher than other disabilities in KP. Nonetheless, the services are focused only on physical disabilities such as physiotherapy and not on SST and social development activities. The equipment and other assistive devices at the centres were also completely outdated, such as treadmills, vex therapy devices, knee-joint exercise machines, shoulder pulls, and exercise cycles. The equipment is relatively old and outdated, installed around 1985 in all these institutes, and since then, no modern and latest machinery aligned with the needs of the children with ID has been provided to any institutes. One of the respondents who worked as a manager in one of the selected institutes for mentally and physically restarted children stated:

All equipment and assistive devices in the Institute are out of order or useless for therapies as they were installed some 30 years ago, and since then, no modern device has been installed. I have raised this issue at different meetings with the Directorate's high-ups, but no action has been taken so far.

Other officials of almost all Special Education centres/institutes said:

Though we provide physiotherapy services to children with all types of disability, however, there is a dire need for other services, such as speech therapy, music therapy, and social skill therapy, which are non-existent. These services play a vital role in the social development of children with IDs.

As mentioned earlier, intellectual disability has not been recognized as a social problem by society so far; consequently, it affects a substantial number of children and their families. However, due to the lack of reliable data on the disability ratio in Pakistan, understand differently abled children's needs is next to imagining. The government has established special education centres in various KP districts, but neither the number is enough to cater to the available children with IDs nor the services available at the centres are adequate. The data also 
showed that equipment and assistive devices in the centres were almost outdated and nonfunctional, severely affecting the treatment and rehabilitation of children with disabilities.

Besides equipment, some other services were desired for these children but did not exist at the centres. The study respondents who worked at these centres demanded funds from the government to upgrade these institutes. Besides, NGOs could also be taken on board to provide the necessary SST skills at the centres. According to studies conducted in India, the primary help sources for children with IDs and learning disabilities are their families and community (Rao \& Suryaprakasam, 2004). However, handling such a child also needs training and education while parents lack appropriate skills. With the scarcity of resources and low priority for children with IDs, public sector institutes lack professional training and equipment. Ahmed (2015) argues that institutional support can reduce the burden on the caregivers and parents of differently abled children. Parents do expect and hope that their children would receive the needed services at the institutes, but that is not the case in many public sector special education units around KP.

\subsection{The Most Needed Services at the Centres are Speech Therapy Services but were Found as the Most Neglected Ones at the Same Time}

As referred above, speech therapy was the most needed service for children with intellectual disability, especially in Down syndrome, autistic and other slow and moderate intellectually disabled children. Speech therapy emphasizes communication, which benefits such children for interaction effects in a variety of settings. Speech therapy aims at providing adequate skills for interaction at a fundamental level. Speech therapy required specially trained teachers and devices to help children with ID communicate with their peers, parents, and teachers. However, the data shows that neither of the services was available at all the centres. The researchers personally observed the condition of the services and found them outdated and inadequate. Further, the researchers inquired from the teachers, administrators, and technical staff regarding the centres' speech therapy services, who also confirmed the researchers' observation and concerns. One of the respondents stated that "Speech therapy and auricular therapy is one of the inevitable needs; however, they are non-existent due to non-availability of funds." 2

Due to the lack of speech therapies and auditory therapeutic services, not only children suffer but also their parents. Besides, mothers are over-burdened with the care of children with special needs that cause fatigue, anxiety, and social exclusion in them (Ahmed et al., 2016). If special education centres performed their duties well, it would reduce the burden on caregivers and mothers. Due to the non-availability of these services, the parents need to look for alternatives treatment centres that are too costly. Hence, the children suffering from IDs face the brunt of meagre services, but their parents are also under tremendous pressure. For instance, a father, while sharing his views, said:

My child has both hearing and speech problems. As there is no speech therapist at this Institute, I need to consult a private doctor who charges Rs. 600/- for each session. That is an awful lot of money for me, but I have no choice.

It was found in some of the public sector institutions around the province; there is a separate section for CIDs such as Peshawar, Haripur, Mardan, and Nowshera. The services required for the rehabilitation of these children are under graded. These institutes were designed and 
established in the 1980s for handling physically/orthopedically disabled children. Similarly, other sections for visually and hearing/speech-related disability were also established. However, since then, no modification and improvement were brought in the sector for overcoming the disabilities of such children and fulfil their unique needs. Intellectually disabled children are dealt with a policy commonly known as the "time-passing policy." There were no equipment, professionals, and environment for their training and rehabilitation. As a result, such children remained dependent on the family, and their parents suffer endless agonies due to their disability.

Besides, more studies show that the families having children with autism spectrum disorder and mild ID have a low family quality of life that is detrimental not only for the worried and stressed parents but also children with ID (Machalicek et al., 2015). They regress in such a family than progress. Carroll (2010) argues that if services' delivery is tailored to the users' needs, effective partnerships between parents/caregivers and institutions could forge. Thus, lacking proper support to the caregivers at home and paucity of governmental measures to habilitate and rehabilitate children with IDs, the situation is precarious in Khyber Pakhtunkhwa.

\subsection{Lack of Social Skills Training/Daily Living Skills/Adaptive Skills at the Public Sector Institutes}

All three terminologies - social skills, daily living skills (DLS), and adaptive skills are synonymously used at times and referred to as the differently-abled person's training to be independent and socially responsible individual members of society. The prevalence of intellectual disabilities among children has increased, but the professional skills, strategies, and technical experts are non-existent in the selected public sector institutions. The identified centres only imparted physical training and rehabilitation such as physiotherapy or educational activities, including teaching and learning. Paradoxically, differently abled children suffering from ID cannot memorize words or comprehend concepts. They require particular strategies, skills, and equipment to assist the IDs in understanding the concepts. In the developed world, such children are given adaptive and social skill training for living an independent life. However, in the selected institutes, these services and practices were non-existent, and children with IDs had no way to get the needed help to benefit from the teaching and learning sessions at the centres.

Furthermore, the children with IDs need daily living skills like eating, keeping themselves clean, behaving well, toilet training, dressing. Such behaviour learning also needs technical help and a social environment where all the necessary support is available. Ironically, the reality is otherwise in the identified centres. A senior official of the Social Welfare Directorate who also worked as in-charge of a Special Education Institute noted his critical experiences in a very disappointing tone and said:

All the special education institutes focus on employment-oriented education for children with ID; however, such services do not benefit them as they cannot learn due to their learning limitations. They need daily living skills for living an independent life. Moreover, such children need a particular policy and separate independent centres where trained professionals such as speech therapists, psychologists, and doctors could assist and rehabilitate them. 
Similarly, other professionals, such as physiotherapists, being aware of such children's needs, shared their views that speech therapies, medical services, psychological assessments, and social- skills training are non-existent in the government institutes. It negatively affects the children's rehabilitation, ultimately causing socio-economic and psychological agonies for the parents. Moreover, a social caseworker also described the poor state of services at of the centres for physically and mentally disabled children during an interview and stated:

Children with ID require daily life skills; however, we provide them regular education due to lack of special education teachers in the centres. Furthermore, salary ceiling is shallow for teachers with no job structure, which is also a reason for their lack of interest in the job they are hired for.

One of the respondents who administered the section for mentally disabled children at one of the selected centres said:

As far as the children's social training is concerned, we provide daily living skills to these children by involving them in small activities like washing hands, eating, using the toilet, and behaving on different occasions. The purpose of such activities is to evolve the spirit of self-help among children and making them independent.

The training to live appropriately and behave according to the situation requires a social environment and a skilled teacher. Thus, the data shows contrast patterns concerning teaching daily living skills instead of SST absent as per almost all the respondents. Studies show that daily living skills improve the possibilities of independence positive functional outcomes among children with IDs (Kilincaslan et al., 2019; Cranahan et al., 2009). One of the biggest worries of the parents of children with IDs is to provide them safe living and make them productive and independent (Bilgin \& Kucuk, 2010). That is why daily living skills are the most critical part of children's social development with IDs.

The findings show that the social skills training is one of the inevitable needs and should be available in any centre/institutes of the province. Such social skill training can enable the children with ID to perform appropriately in any social situation (such as school, family, neighbourhood, and peer groups). Moreover, DLS training contributes to their quality of social life by reducing their stress and child development (Carter \& Brock, 2014). They are also beneficial for the language and communications skills of children with ID. Practical communication good social skills can help behavioural management, which is primarily a considerable challenge for the parents and professionals. SST plays a crucial role in the rehabilitation of children with IDs.

\subsection{Vocational Training Contributes to Social Development than mere Literacy- Oriented Training}

All the research respondents agreed that vocational training is also an inevitable need for children with mild and moderate intellectual disabilities besides social skill training. Vocational training regularly enhances the learning capabilities of children with IDs at the selected institutes of special education. The training includes sewing, embroidery (hand and machine), electronics, chick making, and canning. The technical and handy crafts-making skills 
can increase the chances of financial independence among children with IDs. All the respondents agreed that priority should be given to vocational training alongside SST and DLS at the special education centres. If taught these skills at the institutes, such training pieces can enable them to live financially self-supporting and help them survive independently in society.

Nevertheless, only two out of the selected centres offered vocational training while others did not impart them. Like SST, vocational training is also a neglected area at the special education institutes in KP. Latest studies show that vocational training reduces the support needs in differently-abled persons (Lee et al., 2020; Parmenter, 2011).

One of the respondents who worked at one of the special education centres stated:

We do not have trained and professional vocational trainers in these institutes. Moreover, even a trainer is made available, and they had no professional skills to impart vocational training to the children with IDs as they cannot learn in normal ways; instead, they need more sophisticated and modern techniques.

Children with IDs are at the highest risk of being excluded from society due to their inability to support themselves financially. However, meaningful employment develops a sense of identity and social status and is essential for the psychological wellbeing and inclusion of persons with IDs (Parmenter, 2011; Urwin et al., 2018). Thus, inclusion in the workforce is essential for persons having ID, which is possible through vocational training (von-Barnekow et al., 2017). Also, such training is more effective and helpful for children with mild ID or slow learners as they can be socially trained, educated up to a limited level. However, due to nonavailability or least effective training at the identified centres, children are deprived of the benefits of vocational skills. One of the respondents said:

The positions of the vocational trainer are vacant in these institutes. We have written to the Directorate to provide a vocational teacher, but no action has been taken. The reason for this indifferent attitude is after the $18^{\text {th }}$ amendment, most of the technical staff transferred themselves to their native areas. As a result, a vacuum of such professionals is created. Now, the Directorate is unable to fulfil this vacuum.

The importance of vocational skills and training is understood, but the services are not rendered at the centres, which poses a severe challenge to the possibility of their financial independence and self-reliance. Besides, such training can also overcome the sufferings of their parents and reduce their anxiety. However, the non-availability of such services affects both differently abled children and their parents alike. The government needs to effectively upgrade special education centres with modern equipment and resources to include children with IDs in the future workforce.

\subsection{Poor Welfarizing links with Inadequate Services for Children}

As referred above that the problem of intellectual disability among children has increased over time. However, no updating of facilities and resources has taken place since establishing the selected institutes in KP, mainly in the 1980s. As per the study respondents, the available services are inadequate to fulfil such differently abled children's needs (IDs). Moreover, 
modern assistive devices/equipment, trained professionals, and resources were not available in the centres. This state of indifference is due to poor Welfarization in the province. It is evident from the shortage of trained staff coupled with meagre resources that directly impact children with ID. The study findings show that speech therapists were not available in all the institutes of the province. Moreover, doctors, psychologists, music therapists, vocational trainers, and special education teachers were non-existent. For instance, one of the administrators for the Center for Physically and Mentally Retarded Children shared the shortage of staff and said:

I have only four special education teachers in this centre for a total of 60 children who constitute a teacher-student ratio of 1:20. However, none of them are qualified and trained in special education.

Another respondent who also worked as a Head of Centre in another district said:

We face an acute shortage of funds every year. Sometimes sanctioned funds are released with a delay of four to six months, so picking and dropping services is endangered. However, I pay for fuels from my own pockets, and every year the department owes me money, which is a sorry state of affairs. I am paying this amount because I am a child with a physical and intellectual disability. I understand the importance of special education schools and training for such children.

Similarly, another officer also confirmed the shortage of funds and said:

Due to a shortage of funds, the centres' children have been deprived of the most critical services, including speech therapies. Those children having Autism ${ }^{3}$ essentially need speech therapy services, but the speech therapists are not available in the two of the centres.

Besides the shortage of funds and staff, lack of job structure, and Human Resource Development opportunities for special education and social welfare employees at the Directorate of Khyber Pakhtunkhwa is another indicator of poor Welfarization in the province. The Social Welfare and Special Education department employees complained about the lack of promotion from one grade to another. As a result, the staff members lacked interest and enthusiasm in their job. One of the study participants noted:

I have served this department for 26 long years and will retire in grade 18 next year. My class fellows who joined other departments in the same year will retire in grade 20 and 21, but I could not get a promotion due to a lack of job structure. This problem is affecting the efficiency of the staff members and blocking talented human resources from being inducted. Similarly, many competent staff members left the Institute and joined other departments (Field reflections).

The same problem was shared by the head of the section for mentally disabled children in the Special Education Complex. He said:

After the $18^{\text {th }}$ amendment to the 1973 Constitution of Pakistan, federallyadministered departments working in the provinces were merged with 
provincial ministries. Thus, special education came under the provincial domain. Previously, we enjoyed job satisfaction due to the availability of funds, other facilities, and proper job structure, but after merging, we face severe problems with funds, facilities, and job structure. All the staff members are worried about the future, which is severely affecting their efficiency as well (Field reflections).

Notwithstanding, the public institutes' availability for special education is one positive step, but the quality of services and training is flawed and needs immediate attention. Lack of funding and job structure by the provincial government Hence, the lack of job structure was observed as one of the significant problems that directly affected intellectually disabled children's education and training. Moreover, the official working condition under the Federal Directorate of special education before the $18^{\text {th }}$ amendment was much better; however, the decentralization of the federal social welfare and special education to the provincial Directorate has added to the problems of teaching, training, and admin staff at the public sector special education institutes. Since social welfare is provincial, the federal government does not release any funding for its updating and uplift. Thus, the provincial government's responsibility is to provide the required and essential services and training at special education centres in different KP districts. Ironically, the KP government has failed to take adequate steps to improve the social services and training for the children with IDs and prepare them for the future workforce. Piachaud (2015) argues that social service model prevalent across the Europe needs to change its focus from intended to outcomes. It speaks to the need of the social welfare department to focus more on the intended outcome, which makes the social policy resonant with the needs of the deserved ones.

\section{Conclusion}

The children with intellectual disability constitute the most neglected segments among the disabled population of the society, though the prevalence ratio of such children increases day by day. As for as the services are concerned, there are different sections at five special education schools in the selected districts of the province, which provide various services. As per their official documents, these institutes are supposed to provide physiotherapy, speech therapy, social skills therapy, music therapy, medical services, psychological assessment, vocational therapy, life skills therapy, and cognitive skills training to such children. However, few are available for them, while other necessary services are non-available due to the state's neglected attitude. Social skills training is the need of the hour. The state policies must be guided in this direction.

Children with disabilities live an oppressed and disempowering life due to the state and society's neglected attitude. One of society's social welfare indicators is to see how well differently abled individuals are educated and trained to become productive and independent citizens of society. Furthermore, it is the state's responsibility to provide relief and services to the children with ID and their parents for social inclusion. The provision of adequate social services such as rehabilitative facilities, SST, DLS, and vocational training can help children with IDs to become self-supporting individuals. Since parents of such children worry the most about their future and face social exclusion for having differently abled children, social skills training would reduce their social and economic agonies. However, due to a less social welfare state, both parents and children suffer from ID agonies. 
The inadequate and urban-based services for children with an intellectual disability play an ineffective role in their rehabilitation as rehabilitation is a multi-dimensional and multidisciplinary process in which such children are supported by social caseworkers, psychologists, doctors, speech therapists, auditory therapists, and occupational therapists to prepare them for living an independent life. Owing to the non-existent social skill training for such children's rehabilitation, children and their parents pass through agonies. Such children and their parents are voiceless entities, as they cannot advocate their rights due to intellectual limitation, and the socio-cultural and economic constraints paralyze their parents. Parents having children with intellectual disabilities hide such limitations due to the fear of stigma. Society generally associates such children's birth with the parents' sins and wrong actions in the rural society of KP. As a result, such children mainly restrict to home. However, the parents who approached special education centres intended to have breathing space for managing household activities as they required full-time care. Most of the parents who fail to provide them care are facing mislay of their children.

The unsatisfactory state of services is due to seeing 'social welfare' as charity-oriented rather than professional activity in Pakistan that provides short-term services to orphans, old, destitute, and women. Like other provinces, the Social welfare department exists in KP but is less used to the neediest ones - differently-abled children. Ironically, Pakistan has ratified the UN CRC and UN Convention on the Rights of Persons, emphasizing 'creating a conducive environment for children with special needs (Article 23 UN CRC \& CRPWD article 4). However, welfare remains the most neglected sector and compels such children and their families to live an oppressed and socially excluded life in society. The state's policy should guide and protect the right of the disabled and must provide the required education and skills to ensure their inclusion in the workforce.

\section{References}

Ahmed, S. (2015). A Child with Intellectual Disability and Parental Response: A Comparative Study of Nuclear and Extended Family Structures in Khyber Pakhtunkhwa, Pakistan. Humanities \& Social Sciences Reviews, 3(1), 30-33. https://core.ac.uk/download/pdf/268003843.pdf

Ahmed, S., Ali, J., \& Sanauddin, N. (2016). Patriarchy in Family Caregiving: Experiences of Families of Children with Intellectual Disability in Pakistan. Journal of Postgraduate Medical Institute (Peshawar-Pakistan), 30(1). 73-79. https://vlibrary.emro.who.int/imemr/patriarchy-in-family-care-givingexperiencesof-families-of-children-with-intellectual-disability-in-pakistan-2/

Ali and Naz. (2018). Social Transformation Paradhigm: Paradoxes between Traditionalism and Modernism in Pakistan. Journal of Historical Studies, II(IV), 104-116. https://www.bzu.edu.pk/jhs/vol2-1/5.\%20paper\%20on\%20society1.pdf

Barnard, K. E., \& Powell, M. L. (1972). Teaching the Mentally Retarded Child: A Family Care Approach. Mosby.

Bilgin, H., \& Kucuk, L. (2010). Raising an Autistic Child: Perspectives from Turkish mothers. Journal of Child and Adolescent Psychiatric Nursing, 23(2), 92-99. https://doi.org/10.1111/j.1744-6171.2010.00228.X

Brooks, B. A., Floyd, F., Robins, D. L., and Chan, W. Y. (2015). Extracurricular Activities and the Development of Social Skills in Children with Intellectual and Specific Learning 
Disabilities. Journal Intellectual Disability Research, 59(7), 678-687. https://doi.org/10.1111/jir.12171

Browning, E. R., Caro, P., \& Shastry, S. P. (2011). Cross-Cultural Considerations Regarding Inclusion and Service Provision for Children with Disabilities in India. Journal of International Special Needs Education, 14(1), 32-39. https://eric.ed.gov/?id=EJ922794

Carroll, C. (2010). It is not Every Day that Parents Get a Chance to Talk like this: Exploring Parents' Perceptions and Expectations of Speech-language Pathology Services for Children with Intellectual Disability. International Journal of Speech-Language Pathology, 12(4), 352-361. https://doi.org/10.3109/17549500903312107

Carter, E. W., Trainor, A. A., Cakiroglu, O., Swedeen, B., \& Owens, L. A. (2010). Availability of and Access to Career Development Activities for Transition-age Youth with Disabilities. Career Development for Exceptional Individuals,33(1), 13-24. https://doi.org/10.1177\%2F0885728809344332

Carter, E. W., Brock, M. E., \& Trainor, A. A. (2014). Transition assessment and planning for youth with severe intellectual and developmental disabilities. The Journal of Special Education, 47(4),

245-255. https://journals.sagepub.com/doi/abs/10.1177/0022466912456241

Cobb, R. B., \& Alwell, M. (2009). Transition Planning/Coordinating Interventions for Youth with Disabilities: A Systematic Review. Career Development for Exceptional Individuals, 32(2), 70-81. https://doi.org/10.1177\%2F0885728809336655

Carnahan, C., Musti-Rao, S., \& Bailey, J. (2009). Promoting Active Engagement in Small Group Learning Experiences for Students with Autism and Significant Learning Needs. Education and treatment of Children, 37-61. https://www.jstor.org/stable/42900006?seq=1

Crnic, K. A., Neece, C. L., McIntyre, L. L., Blacher, J., \& Baker, B. L. (2017). Intellectual Disability and Developmental Risk: Promoting Intervention to Improve Child and Family Wellbeing. Child Development, 88(2), 436-445. https://doi.org/10.1111/cdev.12740

Dawn $\left(2015, \quad\right.$ April $\left.5^{\text {th }}\right)$. The Autism Puzzle. Sunday Magazine. https://www.dawn.com/news/print/1173610

Denny, M.R. (1964). Research in Learning and Performance. In: H. A. Stevens and R. Heber. (1964) (Eds.) Mental Retardation: A Review of Research. University of Chicago.

Drew, J. C., Logan, R. D. \& Hardman, L. M. (1986). Mental Retardation: A Life-Cycle Approach $\left(3^{\text {rd }}\right.$ ed). Pearson College Div.

Elliott, C., Pring, T., \& Bunning, K. (2002). Social Skills Training for Adolescents with Intellectual Disabilities: A Cautionary Note. Journal of Applied Research in Intellectual Disabilities, 15(1), 91-96. https://onlinelibrary.wiley.com/doi/abs/10.1046/j.1360-2322.2001.00091.x

Government of Khyber Pakhtunkhwa. (2011). Millennium Development Goals: A Study and Report Compiled with the United Nations Fund for Development (UNDP). Peshawar.

https://reliefweb.int/report/pakistan/khyber-pakhtunkhwa-millenium-development-goalsreport-2011

Hughes, C., Golas, M., Cosgriff, J., Brigham, N., Edwards, C., \& Cashen, K. (2011). Effects of a Social Skills Intervention among High School Students with Intellectual Disabilities and Autism and their General Education Peers. Research and Practice for Persons with Severe Disabilities, 36(1-2), 46-61. https://doi.org/10.2511\%2Frpsd.36.1-2.46 
Rappaport, J. (1977). Community Psychology: Values, Research, and Action. Holt, Rinehart and Winston.

Rappaport, J., \& Seidman, E. (Eds.). (2012). Handbook of Community Psychology. Springer Science \& Business Media.

Keiffer, C. (1984). Citizen Empowerment: A Developmental Perspective. Prevention in Human Services, 3(16), 9-35. https://doi.org/10.1300/J293v03n02_03

Kern, L., Delaney, B. A., Hilt, A., Bailin, D. E., \& Elliot, C. (2002). An Analysis of Physical Guidance as Reinforcement for Noncompliance. Behaviour Modification, 26(4), 516536. https://doi.org/10.1177\%2F0145445502026004005

Kilincaslan, A., Kocas, S., Bozkurt, S., Kaya, I., Derin, S., \& Aydin, R. (2019). Daily Living Skills in Children with Autism Spectrum Disorder and Intellectual Disability: A Comparative Study from Turkey. Research in Developmental Disabilities, 85, 187196. https://doi.org/10.1016/j.ridd.2018.12.005

Lee, K., Cascella, M., \& Marwaha, R. (2020). Intellectual Disability. StatPearls [Internet]. Treasure Island (FL). Stat Pearls.

Machalicek, W., Lang, R., \& Raulston, T. J. (2015). Training Parents of Children with Intellectual Disabilities: Trends, Issues, and Future Directions. Current Developmental Disorders Reports, 2(2), 110-118. https://link.springer.com/article/10.1007/s40474-015-0048-4

Moran, T., Taliaferro, A., \& Pate, J. R. (2014). Confronting Physical Activity Programming Barriers for People with Disabilities: The Empowerment Model. Quest, 66(4), 396408. https://doi.org/10.1080/00336297.2014.948687

Moran, T. E., \& Block, M. E. (2010). Barriers to Participation of Children with Disabilities in Youth Sports. Teaching Exceptional Children Plus, 6(3). 2-13. http://citeseerx.ist.psu.edu/viewdoc/download?doi=10.1.1.673.779\&rep=rep1\&type $=$ pdf

Morgan, D. P., \& Jenson, W. R. (1988). Teaching Behaviourally Disordered Students: Preferred Practices. Merrill Publishing.

Murray, W.E. (2009). Neoliberalism, Globalization, and Development. International Encyclopaedia of Human Geography. https://www.sciencedirect.com/topics/earthand-planetary-sciences/neoliberalism

O' Handley, R. D., Ford, W. B., Radley, K. C., Helbig, K. A., \& Wimberly, J. K. (2016). Social Skills Training for Adolescents with Intellectual Disabilities: A School-based Evaluation. Behaviour Modification, 40(4), 541-567. https://doi.org/10.1177\%2F0145445516629938

Peter, T. J. \& Waterman, R.H. (1982). In Search of Excellence. Harper and Row.

Piachaud, D. (2015). The Future of Social Policy: Changing the Paradigm. Asia \& the Pacific Policy Studies, 2(1), 1-7. https://onlinelibrary.wiley.com/doi/full/10.1002/app5.69

Pritchard, D. G. (1963). Education and the Handicapped. Routledge.

Rao, L. G., \& Suryaprakasam, B. (2004). Effective Teamwork in Special Schools for Children with Intellectual Disabilities in India. Journal of Policy and Practice in Intellectual Disabilities, 1(2), 79-87. https://doi.org/10.1111/j.1741-1130.2004.04012.x

Rose, S. M., \& Black, B. L. (1985). Advocacy and Empowerment: Mental Health Care in the Community. Routledge.

Schalock, R.L., Buntinx, W., Borthwick-Duffy, A., Luckasson, R., Snell, M., Tasse, M., \&Wehmeyer, M. (2007). User's Guide: Mental Retardation: Definition, Classification, and Systems of Support (10 ${ }^{\text {th }}$ ed.). American Association on Intellectual Disability and Developmental Disabilities. 
Spence, S. H. (2003). Social Skills Training with Children and Young People: Theory, Evidence, and Practice. Child and Adolescent Mental Health, 8(2), 84-96. https://doi.org/10.1111/1475-3588.00051

Sukhodolsky D. G., Butter E. M. (2007). Social Skills Training for Children with Intellectual Disabilities. In: Jacobson J. W., Mulick J. A., Rojahn J. (eds). Handbook of Intellectual and Developmental Disabilities. Issues on Clinical Child Psychology. Springer. https://doi.org/10.1007/0-387-32931-5_30

Parmenter, T. R. (2011). Employment Sector Employment Working Paper No. 103. http://wcmstraining2.ilo.org/wcmsp5/groups/public/---ed_emp/--ifp_skills/documents/publication/wcms_167316.pdf

Unwin, G. L., Stenfert, K. B., \& Blumson, J. (2018, November). An Evaluation of a Mental Health Promotion Programme to Improve Emotional, Social and Coping Skills in Children and Young People Attending Special Schools. In:Frontiers in Education (Vol. $3, \quad$ p. $\quad$ 93). https://www.frontiersin.org/articles/10.3389/feduc.2018.00093/full

Von-Barnekow, A., Bonet Codina, N., \& Tost Pardell, D. (2017). Can 3D Gamified Simulations be Valid Vocational Training Tools for Persons with Intellectual Disabilities? A Pilot Based on a Real-life Situation. Methods of Information in Medicine, 56(2), 162-170. http://hdl.handle.net/2117/102971

World Health Organization (1994). The International Classification of Diseases $10^{\text {th }}$ Revision (ICD-10) Guide for Mental Retardation. Division of Mental Health and Prevention of Substance Abuse, World Health Organization, Geneva. https://www.who.int/mental_health/media/en/69.pdf 


\section{Annexure I}

Table-1: Statistics of Disability in Pakistan - 1998 Census

\begin{tabular}{|l|c|c|}
\hline Forms of disability & Numbers & Percentage \\
\hline Visually Impaired & 263452 & $8 \%$ \\
\hline Hearing and Speech limitation & 263452 & $8 \%$ \\
\hline Physically Disabled & 625699 & $19 \%$ \\
\hline Intellectually Disabled & 461043 & $14 \%$ \\
\hline Multiple Disability & 263452 & $8 \%$ \\
\hline Others (not specified) & 1416057 & $43 \%$ \\
\hline Total & $3,293,155$ & 100 \\
\hline
\end{tabular}

Source: Government of Pakistan (1998), Population Census Organization, Islamabad

Table-2: Types of Respondents

\begin{tabular}{|l|l|c|}
\hline $\begin{array}{l}\text { S. } \\
\# .\end{array}$ & Type of Respondents & Frequency \\
\hline 1 & Head of Institution & 5 \\
\hline 2 & Teachers & 10 \\
\hline 3 & Physiotherapists & 5 \\
\hline 4 & Social Caseworkers & 5 \\
\hline & Total & 25 \\
\hline
\end{tabular}

Table-3: Availability of Services in the Target Institutions in Khyber Pakhtunkhwa

\begin{tabular}{|l|c|c|c|c|c|}
\hline Therapy/Center & Hayatabad & Bashirabad & Nowshehra & Mardan & Haripur \\
\hline Physiotherapy & + & + & + & + & + \\
\hline Speech Therapy & - & - & - & - & - \\
\hline Social Skills Therapy & + & - & - & - & - \\
\hline Music Therapy & + & - & - & - & + \\
\hline Medical Services & - & - & - & - & - \\
\hline Psychological Assessment & - & - & - & - & - \\
\hline Vocational Therapy & + & - & - & - & - \\
\hline Life Skills Therapy & + & - & - & - & - \\
\hline Cognitive Skills Training & + & - & - & - & - \\
\hline
\end{tabular}

In the above table, "+" indicates the availability of services, whereas "_" indicates non- availability. 


\section{Annexure II}

\section{Interview Guide:}

1. How does intellectual disability among children in terms of numbers look as compared to other disabilities in KP?

2. Why are the numbers of children with IDs are on the rise, and is there a proper mechanism to deal with the problem?

3. How is the government strategizing to deal with the issue? Are there any specific arrangements and policies for children with IDs in the province?

4. What resources do you have at your institute to properly educate children with ID? Would you say you have updated equipment and skills in this regard? If no, why?

5. How the public sector special institutes provide speech therapy services to children with IDs?

6. Daily living/life skills play a vital role in the rehabilitation of children with ID. Do you focus on that, and how?

7. Any vocational skills training for the children with IDs at your institute or other public sector special education centres around the province to help them become self-reliant and become productive citizen?

8. What kind of vocational skills you provide? Do you rate them adequate and updated? If no, why?

9. Does the government fund adequately to upgrade the special education institutes to meet the needs of the children with IDs? If yes, how? If no, why?

10. Are there any other organizations or institutions that might help promote the special training services at the special education institutes in KP? Who do you think can help other than the government?

11. How do you see the rehabilitation of differently-abled children in coming years? What steps are needed to improve the existing state of the public sector special education institutes?

\section{Notes:}

${ }^{1}$ Pakistan ratified the United Nation Convention on the Rights of Children (UNCRC) and Convention on the Rights of Persons with Disability which requires ensuring full development of children with disabilities.

${ }^{2}$ Field Notes, Physiotherapist's view at special education centre)

${ }^{3}$ According to American Psychiatric Association (2013), "it is a lifelong developmental disability which mostly found among children with deficits in social communication and social interaction and restricted, repetitive patterns of behaviour, interests, or activities". It is also known as Autism Spectrum Disorder (ASD). 